\title{
Survey of community perception of genetic implications of consanguineous marriage in almadina almunawwarah area in Saudi Arabia
}

\begin{abstract}
The objective of this cross-sectional study was to determine the prevalence and patterns and determinants of consanguineous marriage among a representative population from Almadina Almunawwarah Province, in the Kingdom of Saudi Arabia. This area is known to attract Saudis from different parts of the country because it is in the heart of this religious region. A total of 1318 Saudis; 567(43.02\%) females and 751(56.98\%) males, participated in this research. During the period between February and June 2014, each participant was interviewed before completing a pre-structured questionnaire about attitude from consanguineous marriage and other specific socio demographic factors. The response of males towards consanguinity was significantly higher as compared to that of females $(61.78 \%$ in males versus $43.74 \%$ in females). Similarly, a significant positive preference was recorded among older respondents, regardless of the gender. The results showed that the perception of the consequences was significantly higher among educated $(61.98 \%)$ participants and in urban areas $(70.92 \%)$ than among uneducated $(28.95 \%)$ and in those living in rural areas (32.14\%). Further, the degree of awareness of the problem was much higher among males than females (38.22\% and $56.26 \%$, respectively). These figures place Almadina population among the country regions with a high rate of consanguineous marriages. Health education of pre-marriage age people is needed.
\end{abstract}

Keywords: almadina almunawwarah, consanguineous marriage, Saudi Arabia, socio demography
Volume 2 Issue 4 - 2015

\author{
Ahmad M Khalil,' Haytham M Daradka² \\ 'Department of Biological Sciences, Yarmouk University, Jordan \\ ${ }^{2}$ Department of Biology, Taibah University, Saudi Arabia
}

Correspondence: Ahmad M Khalil, Department of Biological Sciences, Yarmouk University, Irbid, Jordan, Tel 0096279992329 Fax009622721117,Email kahmad76@yahoo.com

Received: August 28, 2015 | Published: October 07, 2015

\section{Introduction}

The term consanguineous is derived from two Latin words "con" meaning common, or of the same and "sanguineus" meaning blood. Thus, it refers to a relationship between two people who share a common ancestor or blood. Cousin marriage (seconddegree cousins or closer) is the marriage among people who have at least one grandparent. However clinical genetics, cousin marriage conventionally describes marriages between couples who are related as second cousins or closer. ${ }^{1,2}$ The attitude towards such marriages varies considerably across cultures and legal jurisdictions; being ideal and actively preferred or uncommon but still legal or incest and legally prohibited. Marriages between first and second cousins account for over $20 \%$ of marriages worldwide. ${ }^{1}$ Though the incremental risk enhancement is relatively small, according to many studies several genetic disorders, congenital malformations and reproductive wastage are more frequent in consanguineous marriages. The major harmful effect of consanguinity is a higher frequency of autosomal recessive diseases in the offspring and frequently an increased rate of morbidity and mortality. ${ }^{3-5}$ In many cultures, only certain specific types of such marriages are permitted, while others are not. In western culture, they have been legal in most jurisdictions and were considered socially acceptable until the first half of the 20th century. In the majority of the US States cousin marriages are illegal under the statutes passed in the $19^{\text {th }}$ And $20^{\text {th }}$ centuries. ${ }^{5}$ However, in recent years, cousin marriages are often stigmatized in parts of the Western world. ${ }^{4}$ Supporters of cousin marriage in the West consider legal bans as discrimination, while opponents may appeal to morality or other arguments. ${ }^{4}$ Consonant with this cultural diversity, the attitude of different religions on the question of cousin marriage is also diverse. In Hinduism, the marriage until the degree of 6th cousin if the relationship is entirely agnatic (i.e. the man and woman have the same surname; the entire chain of relationship consists purely of men) is forbidden. However, marriage between second cousins if the man and woman are related in other ways is permitted. ${ }^{5,6}$ In South India, among the Iroquois and certain other North American First Peoples, Indigenous Australians and the Maori of New Zealand, cross cousin marriages are permitted while parallel cousin (father's brother's daughter - FBD) marriages are prohibited. ${ }^{5}$ In the East, South Korea is particularly restrictive with bans on marriage out to third cousins, with all couples having the same surname and region of origin having been prohibited from marrying until 1997. Taiwan, North Korea, and the Philippines also prohibit first-cousin marriage. ${ }^{3}$ It is allowed in Japan, though the incidence has declined in recent years. ${ }^{5}$ China has banned it since passing its 1981 Marriage Law. 5,7

In the Middle East, mostly in Arab countries, cousin marriage is not only allowed, but is common and strongly encouraged. Consanguinity rates show wide variations among Arab countries (Table 1). In some nations it accounts for more than $50 \%$ of all marriages and the rate of this marriage has increased over previous generations. ${ }^{4,5} \mathrm{~A}$ report by the Dubai-based Centre for Arab Genomic Studies (CAGS) in September 2009 found that many Arab countries display one of the highest rates of consanguineous marriage and genetic disorders, nearly two-thirds of which are linked to consanguinity. Research from CAGS and others suggests consanguinity is declining in Lebanon, ${ }^{17,18}$ Egypt, ${ }^{16,19}$ Bahrain, ${ }^{20}$ and among Palestinians,${ }^{13,21}$ but is increasing in Qatar, ${ }^{10,22}$ Yemen, ${ }^{14,15}$ United Arab Emirates, ${ }^{11,12}$ Morocco, Mauritania 
and Sudan. ${ }^{4}$ Qatar was the last Arab Gulf state to institute mandatory screening in 2009 , mainly to warn related couples who are planning marriage about any genetic risks they may face. The current rate of cousin marriage there is $54 \%$, an increase of $12-18 \%$ over the previous generation. ${ }^{2,10}$ Saudi Arabia has uniquely high rates of cousin marriage among the Middle Eastern countries; the rates of marriage to first or second cousins may exceed 70\%. ${ }^{5,9,23-29}$ Even within the Kingdom, the prevalence of consanguineous marriages differs from one area to another; first cousin marriages being the most prevalent. ${ }^{27,29}$ In some of the regions, second cousin and other marriages between relatives are observed at a high rate. In Saudi Arabia, several genetic disorders (mostly autosomal and X-linked recessive) are frequent. The most thoroughly investigated are sickle cell anemia, haemoglobinopathies, and enzymopathies (glucose-6-phosphate dehydrogenase deficiency). ${ }^{27,29}$ Consanguineous marriages among Arabs are deeply rooted and respected. It has often been favored because it is believed to protect tribal traditions, cultural values from changes through many generations, preserve familial wealth, strengthen family ties, promote family stability, and the region's expanding economies, taking advantages relating to reduction of dowry or bride price or bride wealth payment requirements..$^{5,19,30}$ Other reasons may include geographic proximity, keeping and strengthening family's structure and ties, a closer relationship between the wife and her in-laws. , $^{519,30,31}$

Table I Rate of consanguineous marriages in selected Arab countries

\begin{tabular}{llll}
\hline Arab Country & Consanguinity(\%) & First Cousin Marriage(\%) & Reference (s) \\
\hline Jordan & 63.7 & 91.8 & 8 \\
Saudi Arabia & 51.3 & -- & 9 \\
Qatar & 54 & 64.4 & 10 \\
UA E & 50.5 & 51.9 & 11,12 \\
Palestinian Territories & 44.3 & 51 & 13 \\
Yemen & 40 & 84.8 & 14 \\
Egypt & 44.7 & 71.6 & 15 \\
Oman & 68.8 & 56.2 & 16 \\
\hline
\end{tabular}

Also it is thought to have some protective role(s) against divorce and increase survival of marriages. ${ }^{19}$ In addition, intrafamilial unions is believed to maximize reproduction while minimizing reductions in offspring reproductive value under conditions of chronic intergenerational poverty and inequality. ${ }^{31}$ Close agnatic marriage has also been seen as a result of the conceptualization of men as responsible for the control of the conduct of women. ${ }^{5}$ From the foregoing discussion, it appears that the problem of marriage among relatives is partly economic, and it is also partly cultural. The issue here is not cousin marriage, the issue here is to avoid the disease. In All Arab countries in the Arabian Gulf there is still a great lack of knowledge of this central feature of human kinship structure and

dynamics in the countries owing to a scarcity of reliable data in the past. Therefore, there is need an advanced genetic screening for all prospective married couples. Historically, Almadina Almunawwarah is known to attract Saudis from different parts of the country and other Muslim countries because it is in the heart of a religious region. In this city, the in-marriage existed during the time of Prophet Mohammad (PUH) but probably at less than today's rate; $67.2 \%$, the highest rate in the Kingdom (Table 2). The present study was aimed find clues to these aspects by investigation of a randomly selected population from this Province. Information on the dynamics of consanguinity is important for public health strategy.

Table 2 Variations of consanguinity rates within the different regions in the kingdom of Saudi Arabia

\begin{tabular}{lllll}
\hline Region & Collection period & Sample size & $>$ IC, IC* & Overall* \\
\hline Riyadh & $1995[?]$ & 3,212 & 25.8 & $56.8[$ IC, I.5C, 2C, $<2$ C $]$ \\
Dammam & $1998[?]$ & 1,307 & 39.3 & $52[$ IC, I.5C, 2C, $<2$ C $]$ \\
Al-Baha & $2004-2005$ & 487 & 29 & $42.1[?]$ \\
Al-Jouf & $2004-2005$ & 593 & 34.8 & $53.5[?]$ \\
Assir & $2004-2005$ & 833 & 24.6 & $44.5[?]$ \\
Eastern Province & $2004-2005$ & 1,032 & 33.3 & $57.8[?]$ \\
Gizan & $2004-2005$ & 565 & 33 & $53.5[?]$ \\
Hail & $2004-2005$ & 505 & 25.1 & $48.9[?]$ \\
Madina & $2004-2005$ & 618 & 39.2 & $67.2[?]$ \\
Makka & $2004-2005$ & 2,278 & 32.4 & $55.9[?]$ \\
\hline
\end{tabular}




\begin{tabular}{lllll}
\hline Table continued... & & & \\
Region & Collection period & Sample size & $>$ IC, IC* & Overall* \\
\hline Najran & $2004-2005$ & 472 & 28.4 & $66.7[?]$ \\
Northern Borders & $2004-2005$ & 504 & 31.4 & $63.9[?]$ \\
Qassim & $2004-2005$ & 713 & 29.6 & $46.7[?]$ \\
\hline Riyadh & $2004-2005$ & 2,522 & 42.3 & $60[?]$ \\
Tabouk & $2004-2005$ & 432 & 28.3 & $60[?]$ \\
All Saudi Arabia & $2004-2005$ & II,554 & 33.6 & $56[?]$ \\
\hline
\end{tabular}

Abbreviations [?], unknown year of sampling or unknown types of consanguineous marriages; [>IC], double first-cousin marriage; [IC], first-cousin marriage; $[<I C]$, marriage beyond first-cousins; [I.5C], first-cousin once removed carriage; [2C], second-cousin marriage; [ $2 \mathrm{C}]$, marriage between distant relatives beyond second-cousins. (Adapted from Table I). ${ }^{4,29}$

\section{Subjects and methods}

\section{Study design}

This prospective study was conducted in Almadina Almunawarrah area between February and June 2014 to determine the frequency of preference of consanguineous marriages (consequently the mean coefficient of inbreeding) and examine the influence of sociodemographic factors on consanguinity in this region of the Kingdom of Saudi Arabia. A representative sample of 1318 participants living in various areas of Almadina Province was "selected randomly" to be surveyed. A purpose designed questionnaire was filled by each person after being explained to him/her. The age of the study population ranged from $20<$ to $>40$ years). All information was based on structured face-to-face interviews.

\section{Data analysis}

The dependent variable in this study is 'consanguinity' and is derived from questions that asked the participants about their perception of the relation between consanguineous marriage and a higher risk of genetic diseases. The response categories to these questions were: 1 ); 2 ); 3 ); 4 ; and 5). Of a total of 1500 hired, 182 were excluded from analysis because they declined to be included in the study. No distinction was made between second cousins and distant relatives (beyond second cousins), because data were collected under a single code. Distant relative marriages are also defined as consanguineous but with a degree of relatedness less than that of second cousin (The inbreeding coefficient; $\mathrm{F}<0.0156)$. Social and demographic characteristics of the participant, including age, education level and region of residence are considered explanatory variables. Data were analyzed using SPSS version 19 (SPSS Inc., Chicago, IL, USA) and standard descriptive statistics were used. The analysis was conducted by using univariate (frequency distribution) and bivariate methods. Bivariate analysis was done to obtain the percentage of participants in favor of consanguineous or non-consanguineous marriages for each category of explanatory variables and thus identify the statistically significant correlates of consanguinity. The statistical significance was tested by a w2 test for categorical data, and ANOVA (analysis of variance) for continuous-level data. A p-value of $<0.05$ was considered significant.

\section{Results and discussion}

\section{Prevalence of consanguineous marriages}

The frequency of responses in favor of consanguineous marriages is presented in Table 3 . The data indicate that consanguineous marriage is preferred in Almadina Almunawwarah Province. In the present generation (age 20-39years), the rate of consanguinity preference was low (about $40 \%$ ). This rate significantly increases in the younger generation (age <20years; 69.15\%). Similar trends are observed in respect to gender (higher in males; $61.78 \%$ than in females $43.74 \%$ ). The finding; preference of consanguineous marriage among the studied sample, is in accord with the results in most other Arab countries, such as United Arab Emirates, ${ }^{11,12}$ Syria, ${ }^{32}$ Yemen $^{14}$ and Qatar. ${ }^{10}$ In these countries, the rate has increased because it is generally accepted that the social advantages of consanguinity outweigh the disadvantages.

\section{Profile of consanguineous marriage correlates}

To examine the associations between response consanguinity and different sociodemographic factors, the data were divided into categories of gender, age, place of residence, level of education and marital status. Table 3 summarizes the socioeconomic and demographic correlates of consanguineous marriage in Almadina Almunawwarah. The results indicate that educational level of a person is a very strong variable of response to marriage to nonrelatives in the region of Almadina. The percentage of participants in favor of marriages involving relatives decreases from $(71.05 \%)$ among people with no or low level of education to $(38.03 \%)$ to others with a secondary education or higher. This reverse correlation observed in our study is consistent with those reported in other parts of the Arabic and Islamic world; ${ }^{5}$ Saudi Arabia, ${ }^{9}$ Jordan, ${ }^{33}$ Yemen, ${ }^{14}$ Iran, ${ }^{34}$ Turkey, ${ }^{35}$ Pakistan, ${ }^{5}$ and Afghanistan. ${ }^{36}$ However, the negative effects of education are not pronounced in north Jordan, ${ }^{8}$ Israeli Arab community ${ }^{37}$ and capital city Sana'a, Yemen. ${ }^{15}$ Furthermore, it seems that education among women respondents to the practice of consanguineous marriage is a factor towards understanding and prevention of the deleterious impact of consanguinity on health. Indeed, this was evident from the lower the consanguinity rate recorded among university educated female partners in Jordan, ${ }^{38}$ Tunisia, ${ }^{39}$ and Yemen. ${ }^{14}$ In regard with reports on secular trends in consanguinity, data should be interpreted with some caution since in countries where consanguineous marriage is favored, major regional and ethnic differences in prevalence are commonly observed. ${ }^{5}$ As shown in Table 3, consanguineous marriage is the preferred choice in the in rural regions $(67.86 \%)$ compared to urban areas $(29.08 \%)$ $(\mathrm{P}<0.0283)$. This lower tendency towards consanguineous marriages among people living in the city is in agreement with the previous notation that the highest rates of marriages to close relatives are consistently reported in the more traditional rural areas and among the poorest and least educated in society. ${ }^{5}$ Similar data have been reported elsewhere; Algeria, ${ }^{40}$ Egypt, ${ }^{16}$ Iran,${ }^{34}$ Jordan, ${ }^{8}$ Syria, ${ }^{32}$ and Turkey. ${ }^{41}$ Contrary to this, the urban/rural place of residence is not a significant correlate of consanguinity. ${ }^{2,14,18}$ 
Table 3 The sociodemographic characteristics of respondents from Almadina Almunawwara (Saudi Arabia) by their consanguinity preference

\begin{tabular}{|c|c|c|c|c|}
\hline Back ground & Consanguineous N\% & Non consanguineous N\% & Total & $P$ value \\
\hline \multicolumn{5}{|l|}{ Education } \\
\hline Below Secondary & $346(71.05 \%)$ & I4I (28.95\%) & $487(36.94 \%)$ & \\
\hline Higher & $316(38.02 \%)$ & 515 (61.98\%) & $83 I(63.06 \%)$ & 0.0366 \\
\hline \multicolumn{5}{|l|}{ Residence } \\
\hline Rural & $304(67.86 \%)$ & 144(32.14\%) & $448(34 \%)$ & \\
\hline Urban & $253(29.08 \%)$ & $617(70.92 \%)$ & $870(66 \%)$ & 0.0283 \\
\hline \multicolumn{5}{|l|}{ Age } \\
\hline$<20$ & $65(69.15 \%)$ & $29(30.85 \%)$ & $94(7.13 \%)$ & \\
\hline [20-29] & $223(41.29 \%)$ & $317(58.71 \%)$ & $540(40.98 \%)$ & 0.0314 \\
\hline [30-39] & $197(4 \mid .56 \%)$ & $277(58.44 \%)$ & $474(35.96 \%)$ & \\
\hline$\geq 40$ & $7 \mid(33.81 \%)$ & $139(66.19 \%)$ & $210(15.93 \%)$ & \\
\hline \multicolumn{5}{|l|}{ Gender } \\
\hline Female & $248(43.74 \%)$ & $319(56.26 \%)$ & $567(43.02 \%)$ & \\
\hline Male & $464(61.78 \%)$ & $287(38.22 \%)$ & $75 \mathrm{I}(56.98 \%)$ & 0.0227 \\
\hline \multicolumn{5}{|l|}{ Marital status } \\
\hline Single & $259(62.71 \%)$ & 154(37.29\%) & $4 \mid 3(31.34 \%)$ & \\
\hline Engaged & $132(58.15 \%)$ & $95(41.85 \%)$ & $227(17.23 \%)$ & 0.0371 \\
\hline Married & $208(38.24 \%)$ & $336(61.76 \%)$ & $544(41.26 \%)$ & \\
\hline Divorced & 56 (4I.79\%) & $78(58.21 \%)$ & $134(10.17 \%)$ & \\
\hline
\end{tabular}

\section{Conclusion}

The evidence from this investigation and from recent CAGS surveys and other studies shows that there has been little decline in the preference for consanguinity., ${ }^{2,1316-19}$ In spite of this, cultural practices, especially those pertaining to marriage, have remained largely unchanged; those who are young, illiterate or a lower level of education, have a rural place of residence, are more likely to marry their biological relatives. Thus, specific health education and genetic counseling are needed to increase awareness about the negative health impact of consanguineous marriage on offspring. This can be accomplished by tele health technology education program targeting pre-marriage age group such as group discussions, public presentations and mass communication through available electronic and print media sources.

\section{Acknowledgements}

None.

\section{Conflict of interest}

Author declares that there is no conflict of interest.

\section{References}

1. Modell B, Darr A. Science and society: genetic counseling and customary consanguineous marriage. Nat Rev Genet. 2002;3(3):225-229.

2. Islam MM. The practice of consanguineous marriage in Oman: prevalence, trends and determinants. J Biosoc Sci. 2012;44(5):571-594.
3. Paul DB, Spencer HG. It's OK, we're not cousins by blood: The cousin marriage controversy in historical perspective. PLoS Biol. 2008;6(12):2627-2630.

4. Tadmouri GO, Nair P, Obeid T, et al. Consanguinity and reproductive health among Arabs. Reprod Health. 2009;6:17.

5. Bittles AH. Consanguinity in Context. Cambridge: Cambridge University Press; 2012.

6. Kumar D. Genetic Disorders of the Indian Subcontinent. Netherlands: Kluwer Academic Publishers, AA Dordrecht; 2000.

7. Wang W, Qian C, Bittles AH. Consanguineous marriage in PR China: a study in rural Man (Manchu) communities. Ann Hum Biol. 2002;29(6):685-690.

8. Al-Salem M, Rawashdeh N. Consanguinity in north Jordan: prevalence and pattern. J Biosoc Sci. 1993;25(4):553-556.

9. Al-Husain M, Al-Bunyan M. Consanguineous marriages in a Saudi population and the effect of inbreeding on prenatal and postnatal mortality. Ann Trop Paediatr. 1997;17(2):155-160.

10. Bener A, Alali KA. Consanguineous marriage in a newly developed country: the Qatari population. J Biosoc Sci. 2006;38(2):239-246.

11. Al-Gazali LI, Bener A, Abdulrazzaq YM, et al. Consanguineous marriages in the United Arab Emirates. J Biosoc Sci. 1997;29(4):491-497.

12. Denic S, Aden B, Nagelkerke N, et al. $\beta$-thalassemia in Abu Dhabi: consanguinity and tribal stratification are major factors explaining the high prevalence of the disease. Hemoglobin. 2013;37(4):351-358.

13. Assaf S, Khawaja M. Consanguinity trends and correlates in the Palestinian Territories. J Biosoc Sci. 2009;41(1):107-124. 
14. Jurdi R, Saxena PC. The prevalence and correlates of consanguineous marriages in Yemen: similarities and contrasts with other Arab countries. J Biosoc Sci. 2003;35(1):1-13.

15. Gunaid AA, Hummad NA, Tamim KA. Consanguineous marriage in the capital city Sana'a, Yemen. J Biosoc Sci. 2004;36(1):111-121.

16. Mokhtar MM, Abdel-Fattah MM. Consanguinity and advanced maternal age as risk factors for reproductive losses in Alexandria, Egypt. Eur $J$ Epidemiol. 2001;17(6):559-565.

17. Barbour B, Salameh P. Consanguinity in Lebanon: prevalence, distribution and determinants. J Biosoc Sci. 2009;41(4):505-517.

18. El-Kheshen G, Saadat M. Prevalence of consanguineous marriages among shi'a populations of Lebanon. J Biosoc Sci. 2013;45(5): 675682.

19. Yamamah G,Abdel-RaoufE, TalaatA, et al. Prevalence of consanguineous marriages in South Sinai, Egypt. J Biosoc Sci. 2013;45(1):31-39.

20. Al-Arrayed S, Hamamy $\mathrm{H}$. The changing profile of consanguinity rates in Bahrain, 1990-2009. J Biosoc Sci. 2012;44(3):313-319.

21. Pedersen J. The influence of consanguineous marriage on infant and child mortality among Palestinians in the West Bank and Gaza, Jordan, Lebanon and Syria. Community Genet. 2002;5(3):179-181.

22. Sandridge AL, Takeddin J, Al-Kaabi E, et al. Consanguinity in Qatar: knowledge, attitude and practice in a population born between 1946 and 1991. J Biosoc Sci. 2010;42(1):59-92.

23. Chaleby K, Tuma TA. Cousin marriages and schizophrenia in Saud Arabia. Br J Psychiatry. 1987;150:547-549.

24. Serenius F, Edressee AW, Swailem AR. Characteristics of the obstetric population in a Saudi maternity hospital. Acta Paediatr Scand Suppl.1988;346:29-43.

25. Saedi-Wong S, Al-Frayh AR, Wong HYH. Socio-economic epidemiology of consanguineous matings in the Saudi Arabian population. J Asian Afr Stud. 1989;24(3-4):247-252.

26. Zakzouk S, El-Sayed Y, Bafaqeeh SA. Consanguinity and hereditary hearing impairment among Saudi population. Ann Saudi Med. 1993;13(5):447-450.

27. El-Hazmi MAF, Al-Swailem AR, Warsy AS, et al. Consanguinity among the Saudi Arabian population. J Med Genet. 1995;32(8):623-626.
28. Al-Abdulkareem AA, Ballal SG. Consanguineous marriage in an urban area of Saudi Arabia: rates and adverse health effects on the offspring. $J$ Community Health. 1998;23(1):75-83.

29. El-Mouzan MI, Al-Salloum AA, Al-Herbish AS, et al. Regional variations in the prevalence of consanguinity in Saudi Arabia. Saudi Med J. 2007;28(12):1881-1884.

30. Saadat M. Association between consanguinity and survival of marriages Egypt J Med Human Genet. 2015;16(1):67-70.

31. Chisholm JS, Bittles AH, Consanguinity and the developmental origins of health and disease. J Evolution Med. 2015;3:4

32. Othman H, Saadat M. Prevalence of consanguineous marriages in Syria J Biosoc Sci. 2009;41(5):685-692.

33. Hamamy H, Jamhawi L, Al-Darawsheh J, et al. Consanguineous marriages in Jordan: why is the rate changing with time? Clin Genet. 2005;67(6):511-516.

34. Givens BP, Hirschman C. Modernization and consanguineous marriage in Iran. J Marriage Fam. 1994;56(4):820-834.

35. Demirel S, Kaplanoglu N, Acar A, et al. The frequency of consanguinity in Konya, Turkey, and its medical effects. Genet Couns. 1997;8(4):295-301.

36. Saadat M, Tajbakhsh K. Prevalence of consanguineous marriages in West and South Afghanistan. J Biosoc Sci. 2013;45(6):799-805.

37. Jaber L, Halpern GJ, Shohat T. Trends in the frequencies of consanguineous marriages in the Israeli Arab community. Clin Genet. 2000;58(2):106-110.

38. Khoury SA, Massad D. Consanguineous marriage in Jordan. Am J Med Genet. 1992;43(5):769-775.

39. Kerkeni E, Monastiri K, Saket B, et al. Association among education level, occupation status, and consanguinity in Tunisia and Croatia. Croat Med J. 2006;47(4):656-661.

40. Zaoui $\mathrm{S}$, Biemont $\mathrm{C}$. Frequency of consanguineous unions in the Tlemcen area (West Algeria). Sante. 2002;12(3):289-295.

41. Alper OM, Erengin H, Manguoglu AE, et al. Consanguineous marriages in the province of Antalya, Turkey. Ann Génét. 2004;47(2):129-138. 